BRUHN, F.R.P. et al. Neosporose em ruminantes. PUBVET, Londrina, V. 6, N. 2, Ed. 189, Art. 1276, 2012.

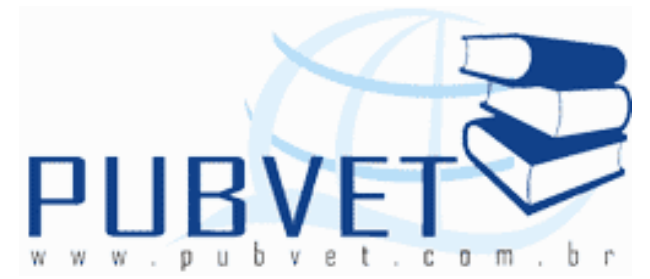

PUBVET, Publicações em Medicina Veterinária e Zootecnia.

\title{
Neosporose em ruminantes
}

Fábio Rapahel Pascoti Bruhn ${ }^{1 *}$, Tiago da Silva Teófilo², Andréa Krystina Vinente Guimarães ${ }^{3}$, Ronaldo Francisco de Lima ${ }^{2}$, Gislaine da Silva Andrade ${ }^{4}$, Antônio Marcos Guimarães ${ }^{5}$

${ }^{1}$ Médico Veterinário, Mestrando em Ciências Veterinárias, Universidade Federal de Lavras - UFLA, Lavras-MG;

${ }^{2}$ Médico Veterinário, Doutorando em Zootecnia, UFLA;

${ }^{3}$ Engenheira Agronôma, Doutora em Zootecnia, UFLA;

${ }^{4}$ Biológa, Mestre em Ciências Veterinárias;

Prof. ${ }^{5}$ Doutor em Parasitologia, DMV, UFLA.

*Autor para correspondência: fabio_rpb@yahoo.com.br

\section{Resumo}

A neosporose é uma doença infecciosa, causada pelo Neospora caninum, protozoário intracelular obrigatório, formador de cistos, tendo o cão como principal hospedeiro definitivo. Este pode contaminar água e alimentos destinados a ruminantes, transmitindo assim a doença. Trata-se de uma das principais causas de abortos, gerando expressivos prejuízos econômicos na produção destes animais. A prevalência pode variar bastante em função do sistema de criação. Vários fatores de risco são associados a ocorrência da neosporose em ruminantes, dentre eles está a presença de cães em áreas destinadas a criação desses animais. O diagnóstico pode ser feito por métodos 
BRUHN, F.R.P. et al. Neosporose em ruminantes. PUBVET, Londrina, V. 6, N. 2, Ed. 189, Art. 1276, 2012.

sorológicos, com intuito de eliminar os animais positivos do rebanho e ainda por técnicas moleculares e histopatológicas. Como o conhecimento desta doença ainda é limitado, o objetivo desta revisão é mostrar os aspectos mais relevantes sobre a neosporose em ruminantes.

Palavras-chave: epidemiologia, aborto, Neospora caninum

\section{Neosporosis in ruminants}

\section{Abstract}

The neosporosis is an infectious disease caused by Neospora caninum, which is an obligate intracellular protozoan cysts forming, with the dog as the main definitive host. This can contaminate water and food destined for ruminants, thus transmitting the disease. This is a major cause of abortions, generating significant economic losses in the production of these animals. The prevalence may vary greatly depending on the farming system.Various risk factors are associated with the occurrence of neosporosis in ruminants, among them is the presence of dogs in areas for the creation of these animals. The diagnosis can be made by serological methods, aiming to eliminate the positive animals from the herd and also by molecular and histopathological techniques. As knowledge of this disease is still limited, the objective of this review is to show the most relevant aspects on neosporosis in ruminants.

Keywords: epidemiology, abortion, Neospora caninum

\section{INTRODUÇÃO}

O Brasil é referência na agropecuária mundial, com um dos maiores rebanhos bovinos, constituído por 177 milhões de cabeças (ANUÁRIO DA PECUÁRIA BRASILEIRA - ANUALPEC, 2010).

A sanidade dos rebanhos é um dos desafios que ainda terão que ser enfrentados para que o Brasil continue se destacando na produção agropecuária. Na criação de bovinos leiteiros, o manejo sanitário é responsável 
BRUHN, F.R.P. et al. Neosporose em ruminantes. PUBVET, Londrina, V. 6, N. 2, Ed. 189, Art. 1276, 2012.

pelo controle de diversas doenças nos rebanhos, como a neosporose, que se configura como uma das mais importantes, por causar distúrbios reprodutivos.

A neosporose é uma doença relativamente recente e comum em muitos países produtores de leite (KAMGA-WALADJO et al., 2010; WILLIAMS et al., 2009), sendo causada pelo Neospora caninum (Apicomplexa: Sarcocystidae). Trata-se de um protozoário que pode infectar canídeos domésticos e silvestres, ruminantes e equinos. O parasito foi descrito e caracterizado pela primeira vez em 1984, e atualmente é considerado como um dos principais agentes causadores de falhas reprodutivas em bovinos no mundo (BASSO et al., 2010).

Devido aos prejuízos econômicos causados por problemas reprodutivos em ruminantes o $N$. caninum deve ser considerado um patógeno importante para estes animais. Estudos sobre a biologia e a epidemiologia deste agente não são bem conhecidos. Com isso, o objetivo desta revisão é mostrar os aspectos mais relevantes sobre a biologia e epidemiologia do $N$. caninum em ruminantes.

\section{AGENTE ETIOLÓGICO}

A neosporose é uma doença causada pelo $N$. caninum, parasito intracelular obrigatório formador de cistos, que pode infectar uma série de hospedeiros de interesse produtivo, como os ruminantes (YAO et al., 2009).

Os prejuízos econômicos causados por este patógeno incluem principalmente as perdas reprodutivas, como retorno ao cio, com intervalos regulares ou irregulares, abortos, nascimento de animais fracos e inviáveis, com sinais neurológicos, ou persistentemente infectados (ALMERIA et al., 2009a; ALMERIA et al., 2010; DUBEY, SCHARES E ORTEGA-MORA, 2007).

A morfologia do $N$. caninum varia de acordo com o ciclo biológico. No estágio de taquizoítos possuem um formato ovóide, lunar ou globular, medem 3-7 x 1-5 $\mu \mathrm{m}$, possuem uma membrana plasmática de três camadas, além de três organelas secretoras diferentes, que participam da invasão, formação e 
BRUHN, F.R.P. et al. Neosporose em ruminantes. PUBVET, Londrina, V. 6, N. 2, Ed. 189, Art. 1276, 2012.

manutenção do vacúolo parasitófago encontrado no citoplasma da célula hospedeira, o que permite a sobrevivência e proliferação do parasito (HEMPHILL, GAJENDRAN e SONDA, 1998).

Os taquizoítos possuem uma multiplicação rápida (do grego tachys=rápido), penetram ativamente na célula hospedeira se dividem rapidamente por endodiogenia, provocando lise celular e infectando novas células. Sua presença no organismo do hospedeiro indica fase aguda ou proliferativa da infecção, transformando-se, a seguir, em bradizoítos quando surge a resposta imune do hospedeiro. Os bradizoítos podem ser reativados e romper o cisto se houver uma queda de imunidade do hospedeiro (WILLIAMS et al., 2009).

Os bradizoítos apresentam multiplicação lenta (do grego bradys=lento), possuem forma alongada, com um núcleo sub-terminal medindo aproximadamente $8 \times 2 \mu \mathrm{m}$. Os bradizoítos contêm organelas tipicamente encontradas em outros coccídios (DUBEY, BARR e BARTA, 2002). Apresentam as mesmas organelas encontradas nos taquizoítos, porém com segmentos membranosos planos e vesículas menores. É capaz de formar cistos intracelulares no interior de tecidos. O cisto possui a forma arredondada, sua parede é lisa, apresentando ramificação e sua espessura depende do tempo da infecção, podendo se apresentar envolta por uma membrana cística que o protege de reações imunológicas e fisiológicas do hospedeiro (FUCHS, SONDA e GOTTSTEIN, 1998).

Os cistos teciduais de $N$. caninum são encontrados em vários tecidos, primariamente em baixo número nos neurais quando comparado aos de T.gondii e podem ficar em latência por meses ou anos, por fim restabelecendo todo o ciclo, quando consumido por um hospedeiro definitivo. Os oocistos de N. caninum são formas infectantes, geralmente com tamanho de $11,7 \times 11,3$ $\mu \mathrm{m}$, transparentes e possuem de 0,6 a 0,8 $\mu \mathrm{m}$ de espessura. Os esporozoítos são alongados e têm geralmente $6,5 \times 2 \mu \mathrm{m}$ de tamanho (DUBEY,BARR e BARTA, 2002). 
BRUHN, F.R.P. et al. Neosporose em ruminantes. PUBVET, Londrina, V. 6, N. 2, Ed. 189, Art. 1276, 2012.

\section{CICLO BIOLÓgICO}

Neospora caninum possui um típico ciclo de vida heteroxeno facultativo, que envolve um hospedeiro definitivo canídeo e uma série de outros hospedeiros intermediários (WILLIAMS et al., 2009). O ciclo biológico do $N$. caninum foi elucidado por McAllister et al. (1998), após confirmação experimental que os canídeos eliminam oocistos nas fezes quando ingerem cistos contidos em cérebro de camundongos infectados, levando a concluir que o cão é um dos hospedeiros definitivos.

O ciclo de vida se caracteriza por três tipos de formas infectantes: oocistos, taquizoítos e bradizoítos. Os oocistos constituem a forma ambientalmente resistente do parasita. Cada oocisto possui em seu interior dois esporocistos, cada um com quatro esporozoítos que são resultantes da multiplicação sexuada gametogônica que ocorre no processo de infecção entero-epitelial em cães (WILLIAMS et al., 2009). Após eliminação nas fezes do hospedeiro definitivo, os oocistos passam por um processo de esporulação, se tornando infectantes (DUBEY, BARR E BARTA, 2002). Segundo Dubey, Schares e Ortega-Mora (2007) cães eliminam oocistos cinco dias ou mais após a infecção primária, sendo que a duração desta eliminação pode ser errática e variar de um a vários dias.

Dentre os possíveis hospedeiros intermediários, o mais comum e importante economicamente é o bovino. Neste tipo de hospedeiro ocorre uma multiplicação assexuada dos taquizoítos dentro de vacúolos parasitóforos de diferentes tipos celulares. Os taquizoítos se diferenciam então em bradizoítos, cuja multiplicação é mais lenta. Nesta forma o parasito mantém a infeç̧ão persistente nos hospedeiros. O estágio de latência não impede a infecção quando são ingeridos pelo cão. Ambas as formas são resultantes da proliferação no processo de infeç̧ão disseminada no ciclo extra-luminal assexuado do parasito (WILLIANS et al., 2009).

De acordo com Dubey, Schares e Ortega-Mora (2007), as três formas estão envolvidas na infecção dos hospedeiros: oocistos presentes no ambiente 
BRUHN, F.R.P. et al. Neosporose em ruminantes. PUBVET, Londrina, V. 6, N. 2, Ed. 189, Art. 1276, 2012.

infectam os hospedeiros intermediários; bradizoítos em cistos teciduais dos hospedeiros intermediários infectam canídeos após ingestão destes tecidos; os taquizoítos passam pela placenta dos hospedeiros intermediários, promovendo a infecção de fetos. Isso ocorre com a reativação dos bradizoítos em taquizoítos que, ao migrar para outros tecidos como o útero, realizam a infecção fetal transplacentária endógena (WILLIAMS et al., 2009).

Neospora caninum possui um ciclo de vida em animais silvestres e outro em hospedeiros domésticos, sendo que nestes ambientes distintos, canídeos domésticos (Canis lupus familiares) e silvestres coiotes (Canis lupus latrans e Canis lupus dingo), que são os hospedeiros definitivos do agente, liberam oocistos nas fezes (DUBEY; LINDSAY, 1996; GODIM et al, 2004; BJORKMAN et al. 2010). Recente discussão tem sido levantada sobre a existência de outros canídeos silvestres de importância epidemiológica com potencial de contaminação ambiental do agente (BJORKMAN et al., 2010), o que poderia constituir um fator de risco a produção animal próxima às áreas de matas. Porém, pouco se sabe sobre a epidemiologia do $N$. caninum relacionada a estas áreas (AGUIAR et al., 2006).

Várias espécies animais podem servir como hospedeiros intermediários do $N$. caninum, sendo os bovinos os mais importantes economicamente (WILLIANS et al., 2009) Sabe-se que camundongos e ratos são consumidos por diferentes espécies de carnívoros, inclusive canídeos. Especula-se que, provavelmente, estes contribuem para a disseminação do parasito (DUBEY, SCHARES E ORTEGA-MORA, 2007).

\section{TRANSMISSÃO}

O protozoário $N$. canimum possui uma ampla distribuição mundial e a transmissão vertical é a sua principal via de propagação da doença (TREES e WILLIANS, 2005). A transmissão vertical assume papel primordial na manutenção da doença (HASLER et al., 2006; YILDZ et al., 2009), pelo fato da 
BRUHN, F.R.P. et al. Neosporose em ruminantes. PUBVET, Londrina, V. 6, N. 2, Ed. 189, Art. 1276, 2012.

maioria das infecções congênitas resultarem em animais clinicamente normais, mas persistentemente infectados.

Em estudo recente foi verificado maior soroprevalência para $N$. caninum em vacas que não apresentaram aborto em relação àquelas que apresentaram aborto, indicando a importância do nascimento de fetos sem sinais clínicos, mas já infectados com o agente, o que permite a manutenção da doença às gerações futuras (YILDZ et al., 2009). Em estudo realizado por Moore et al. (2009) na Argentina, verificou-se que a transmissão vertical possui taxa de infecção de $37,1 \%$ em vacas.

$\mathrm{Na}$ transmissão horizontal, os hospedeiros intermediários ingerem alimentos ou água contaminada com oocisto de $N$. caninum, liberados principalmente pelos cães (BASSO et al., 2010). Esta forma de transmissão também pode acontecer em animais que ingerem cistos presentes em tecidos de qualquer hospedeiro intermediário, como restos de placenta ou sistema nervoso. Dentre os possíveis hospedeiros intermediários está o ser humano. Já foram encontrados anticorpos anti- $N$. caninum no homem, mas não foi possível realizar o isolamento do agente e nem foi encontrado o parasito via métodos moleculares em tecidos de seres humanos (DUBEY, SCHARES E ORTEGAMORA, 2007). A neosporose apresenta um potencial zoonótico ainda em discussão (REITEROVA et al., 2009).

A transmissão vertical tem sido demonstrada em vários hospedeiros (bovinos, carneiros, cabras, cães, gatos, camundongos, macacos e porcos), sendo o principal modo de transmissão em bovinos (TREES e WILLIANS, 2005). Ocorre via materno fetal, pela placenta, sendo que esta infecção pode ser recrudescente ou primária. Um animal infectado pode transmitir a infecção ao feto por sucessivas gestações, contribuindo significativamente para a persistência da infecção no rebanho e pode apresentar um ou mais abortos durante a sua vida reprodutiva acarretando grandes perdas reprodutivas (DUBEY, SCHARES e ORTEGA-MORA, 2007). De acordo com Dubey, Schares e Ortega-Mora (2007), o N. caninum é um dos agentes microbianos com maior capacidade de passar pela placenta dos hospedeiros. 
BRUHN, F.R.P. et al. Neosporose em ruminantes. PUBVET, Londrina, V. 6, N. 2, Ed. 189, Art. 1276, 2012.

Estudos recentes têm demonstrado que o termo "vertical" está dividido em endógena e exógena para descrever duas situações. A primeira se refere à transmissão fetal que ocorre durante a gestação caracterizada como infecção materna, definida como infecção transplacentária endógena. Neste tipo de infecção, os esporozoítos se diferenciam em taquizoítos que, por sua vez, migram pela circulação, provavelmente por meio de células do sistema fagocítico mononuclear para o útero (WILLIAMS et al., 2009).

A segunda se refere à transmissão fetal que ocorre após a reativação da infecção materna pré-natal, sendo esta caracterizada como uma infecção exógena. Neste tipo de transmissão bradizoítos se diferenciam em taquizoítos que migram para o útero, e via placenta realizam a infecção fetal (WILLIAMS et al., 2009).

Outra possível forma de infecção de animais recém nascidos é a lactogênica, principalmente por meio do colostro. Acredita-se que o $N$. caninum seja sensível à acidez estomacal, porém estudos recentes demonstraram que bezerros alimentados com colostro de várias vacas apresentam maior probabilidade de apresentarem a infecção pelo parasito (CORBELLINI et al., 2006).

\section{PATOGENIA E SINAIS CLÍNICOS}

A patogenia do $N$. caninum é complexa e só parcialmente compreendida. Alguns fatores parecem influenciar na ocorrência do aborto, tais como idade do animal, época da infecção, imunidade da mãe durante a gestação, dentre outros, o que determina porque alguns animais soropositivos abortam e outros não. Da mesma forma, o mecanismo preciso pelo qual ocorre aborto em infecções por $N$. caninum é desconhecido (ALMERIA et al., 2010).

Vacas soropositivas gestantes normalmente apresentam um aumento na quantidade de anticorpos anti- $N$. caninum, o que não representa proteção materna ao feto, e sim uma maior taxa de passagem dos parasitos pela placenta e, portanto, uma maior ocorrência de lesões fetais e aborto. De fato, 
BRUHN, F.R.P. et al. Neosporose em ruminantes. PUBVET, Londrina, V. 6, N. 2, Ed. 189, Art. 1276, 2012.

Almeria et al. (2010) demonstrou que vacas com maiores títulos sorológicos apresentam maior propensão ao aborto, provavelmente em função de um aumento na parasitemia, o que justifica as maiores níveis de anticorpos nestes animais.

O aborto ocorre quando as lesões causadas pela proliferação do parasito na placenta ou no feto tornam a gestação inviável. Estas lesões podem ser causadas pela ação do parasito diretamente sobre o feto ou sobre a placenta, o que causa uma diminuição da passagem de nutrientes via placenta (ALMERIA et al., 2010). Neste mesmo estudo, os autores concluíram que as lesões na placenta e no feto, além da forte resposta imune no feto, principalmente em relação à liberação de interferon-gama, são mais importantes na patogenia do aborto que o tempo de infecção das mães gestantes. Essas lesões podem levar ao desenvolvimento dos sinais clínicos e patológicos descritos em casos de neosporose.

O sinal clínico mais importante e evidente em vacas adultas é, de fato, o aborto, que pode ocorrer em qualquer estágio de infecção, mais frequente na segunda metade da gestação (ALMERIA et al., 2010). Porém, além do aborto, os fetos também podem morrer no útero e serem mumificados ou autolisados, pode ainda ocorrer o nascimento de animais apresentando sinais clínicos nervosos ou clinicamente normais, mas persistentemente infectados (ALMERIA et al., 2009a). Normalmente vacas infectadas não apresentam nenhum outro sinal clínico, além destes de caráter reprodutivo (ALMERIA et al., 2010), mas ainda é descrito na literatura redução de produtividade (produção leiteira e ganho de peso) (REITEROVA et al., 2009). Pelo menos parte da variação clínica observada na neosporose pode ocorrer em função da diversidade presente entre os diferentes isolados do agente que infectam os animais de forma natural. Estudos sobre esta diversidade genética são de grande importância ao se considerar a potencial utilização de isolados de baixa virulência na fabricação de vacinas (ROJO-MONTEJO et al., 2009). 
BRUHN, F.R.P. et al. Neosporose em ruminantes. PUBVET, Londrina, V. 6, N. 2, Ed. 189, Art. 1276, 2012.

\section{IMUNIDADE AO N. CANINUM}

A relação entre o sistema imune do hospedeiro intermediário e o $N$. caninum é complexa e depende da rota e da época da primoinfecção (WILLIAMS et al., 2009).

As infecções parasitárias caracterizam-se por estimular inúmeros mecanismos imunológicos de defesa, sejam aqueles mediados por anticorpos ou por células, e a eficiência da resposta imune depende do parasito em questão e do estágio da infecção. De maneira simplificada, após a infecção, ocorre a apresentação do antígeno a outras células do sistema imune, como por exemplo, aos linfócitos T CD4+. Estas células, por sua vez, auxiliam a resposta imune, que pode ser dividida em função do tipo de célula T CD4+ predominante. Depois de proliferada, essas células vão estimular um perfil de citocinas que vai desempenhar um papel específico de maneira mais adequada. Quando há predomínio de células T CD4+ do tipo Th1, há liberação de interleucina-2, interferon-gama e fator de necrose tumoral-alfa e beta, fatores críticos para o desenvolvimento da imunidade anti parasitas intracelulares, assim como a mudança de classe para anticorpos do tipo IgG2. Por outro lado, o predomínio de células T CD4+ do tipo Th2 estimula a liberação de das citocinas interleucina-4, 5, 6, 9, 10 e 13, que são essenciais para a resposta imune por meio de anticorpos, além de estimular a mudança de classe para os anticorpos dos tipos IgG1 e IgE, importantes no combate a parasitas extracelulares (ROITT, BROSTOFF e MALE, 1999). Strohbusch et al. (2009) verificou que taquizoítos de $N$. caninum são capazes de invadir e proliferar em células dendríticas imaturas (células apresentadora de antígeno), e que a presença deste parasito é capaz de propiciar a resposta imune tanto Th1 quanto Th2, por meio do estímulo a liberação de interleucinas 10 e 12 (ROITT, BROSTOFF e MALE, 1999).

Durante uma gestação normal, ocorre um predomínio da resposta do tipo Th2, cujas citocinas inibem a liberação daquelas produzidas após estimulação das células Th1. Porém, o estímulo gerado pela infecção intracelular do $N$. 
BRUHN, F.R.P. et al. Neosporose em ruminantes. PUBVET, Londrina, V. 6, N. 2, Ed. 189, Art. 1276, 2012.

caninum leva a uma mudança neste perfil normal de citocinas, ou seja, da resposta Th2 para Th1 (Almeria et al. 2009b). Segundo Almeria et al. (2010), o interferon-gama liberado fortemente após estimulo de células Th1, apesar de ser mais adequado no combate a parasitos intracelulares, como o $N$. caninum, aumenta a incidência de abortos. Apesar disso, Almeria et al. (2009b) que afirmam que os anticorpos do tipo IgG2, associados ao interferon-gama, ambos liberados na resposta tipo Th1, são fatores de proteção à ocorrência de abortos em vacas soropositivas para o $N$. caninum.

De fato, o balanço no controle do $N$. caninum desempenhado pelo sistema imune da mãe parece ser um fator determinante na ocorrência, ou não, do aborto (ALMERIA et al., 2010). Segundo Almeria et al (2010) mais estudos sobre a expressão do perfil de citocinas são necessários, visando elucidar qual tipo de resposta está mais relacionada ao aborto ou a transmissão transplacentária durante a infecção.

Segundo Williams et al. (2009) e Almeria et al. (2010), vacas já expostas ao $N$. caninum desenvolvem imunidade frente a transmissão horizontal, mas não são capazes de evitar o recrudescimento da doença durante a gestação. Isso significa que o sistema imune de vacas persistentemente infectadas, apesar de ser capaz de resistir ao desafio da transmissão endógena, não é suficiente para conferir proteção ao feto por meio do impedimento da transmissão vertical transplacentária endógena.

\section{DIAGNÓSTICO}

O diagnóstico da neosporose é baseado em avaliações post-mortem (feto abortado) ou in vivo (mãe), neste último por meio de exames que verificam a presença de anticorpos anti- $N$. caninum no soro dos hospedeiros. Segundo Moré et al. (2008), Reichel, Ross e McAllister (2008) e Wapenaar et al. (2007) métodos sorológicos, como RIFI, ELISA e o NAT, são recomendados para o diagnóstico de doenças causadas por protozoários de interesse veterinário, como o $N$. caninum, pois avaliam o contato do agente com o hospedeiro de 
BRUHN, F.R.P. et al. Neosporose em ruminantes. PUBVET, Londrina, V. 6, N. 2, Ed. 189, Art. 1276, 2012.

forma específica por meio da detecção de IgG. De acordo com Wapenaar et al. (2007), a RIFI é o teste com melhor desempenho entre esses três, apesar da subjetividade implícita na sua leitura. Apesar disso, segundo estes mesmos autores, NAT e ELISA, especialmente este último, podem ser mais recomendados para avaliação da presença do $N$. caninum em alguns casos. Isso porque os mesmos são testes não espécie-específicos e, como o parasito possui diferentes espécies hospedeiras, esta vantagem se torna importante na avaliação da neosporose.

Métodos sorológicos são importantes, também nos estudos soroepidemiológicos das doenças. Segundo Hasler et al. (2006), na utilização do ELISA, é preciso ter cautela quando se pretende utilizar o resultado na classificação dos animais de um rebanho entre positivos ou negativos para o agente. Por exemplo, para o controle da neosporose por meio da eliminação de animais soropositivos, o teste pode apresentar resultados falso-negativos ou falso-positivos. Como método molecular pode ser utilizada a Reação em Cadeia de Polimerase (PCR), técnica altamente específica e sensível para o diagnóstico de $N$. caninum (YAO et al., 2009). Esta técnica é aplicada principalmente no diagnóstico post mortem da neosporose em tecidos fetais (SUTEU et al., 2010).

O diagnóstico post mortem também pode ser baseado em avaliação histológica e imunoistoquímica de tecidos oriundos de fetos abortados. Pescador et al. (2007) avaliaram fetos abortados entre três e oito meses de idade e verificaram que $53 \%$ apresentavam cérebros liquefeitos. Microscopicamente, foi observado que a maioria das lesões se concentrava em tecidos musculares, com infiltrado de células mononucleares. Na maioria dos fetos também foi encontrada necrose acompanhada de infiltrado inflamatório mononuclear no tecido pulmonar, que em alguns casos ocupavam quase todo o lóbulo do pulmão, com edema associado. No tecido cerebral foi encontrada encefalite não supurativa e necrose acompanhada de infiltrado inflamatório mononuclear, que também foi verificado nos rins e fígado, mas em menor quantidade. Neste mesmo estudo, após aplicação de técnicas de 
BRUHN, F.R.P. et al. Neosporose em ruminantes. PUBVET, Londrina, V. 6, N. 2, Ed. 189, Art. 1276, 2012.

imunoistoquímica, foi verificada relação $(P<0,01)$ somente entre consistência cerebral (odds ratio $=5,73$ ) e lesões no pulmão (odds ratio $=12,11$ ) com a infecção por $N$. caninum. Estes resultados indicam que o tecido cerebral, mesmo que autolisado é adequado para a aplicação da técnica de imunoistoquímica, e que o tecido pulmonar pode ser usado como auxiliar no diagnóstico presuntivo de aborto causado por N. caninum.

É importante ressaltar que, de acordo com Dubey, Schares e OrtegaMora (2007), apesar de muito importante, o diagnóstico sorológico ou molecular de tecidos fetais não pode ser usado como determinante para se confirmar a neosporose como causa do aborto, em função da alta taxa de bezerros sadios, mas persistentemente infectados, que nascem nesta doença.

\section{PREVENÇÃo E CONTROLE}

Perdas econômicas anuais decorrentes da neosporose chegam a centenas de milhares de dólares por ano no mundo (DUBEY, SCHARES E ORTEGA-MORA, 2007), o que evidência a importância no desenvolvimento de medidas de profilaxia e, portanto, minimização destes custos. O controle efetivo da neosporose é difícil, devido à inexistência de vacinação eficaz. Existem indícios de que as vacinas inativadas produzem um efeito preventivo na transmissão vertical (mãe-filha), porém ainda não foi confirmada a eficiência na prevenção de abortos e os resultados ainda são muito discutidos. Segundo Reichel e Ellis (2009) a vacinação eficaz contra o N. caninum reduziria em até $90 \%$ as perdas econômicas decorrentes deste parasito no longo prazo. Isto demonstra a importância da vacinação e a necessidade de desenvolvimento rápido de uma vacina eficaz contra a neosporose.

O desafio de uma vacina eficaz para a neosporose está no impedimento da primoinfecção de animais e do recrudescimento da doença em animais positivos, evitando assim o aborto (REICHEL e ELLIS, 2009).

Existem drogas experimentalmente eficazes contra o N. caninum. Porém, segundo Reichel e Ellis (2009) o tratamento deve ser iniciado o mais rápido 
BRUHN, F.R.P. et al. Neosporose em ruminantes. PUBVET, Londrina, V. 6, N. 2, Ed. 189, Art. 1276, 2012.

possível, antes que os sinais clínicos se tornem irreversíveis, além de ser muitas vezes economicamente inviável. Apesar disso, de acordo com Dubey, Schares e Ortega-Mora (2007) com um maior conhecimento nas relações parasito-hospedeiro durante a gestação, diferentes estratégias de tratamento podem ser recomendadas em rebanhos com altos índices de transmissão transplacentária endógena e exógena. Apesar de que, segundo estes mesmos autores, atualmente ainda não existe drogas seguras e eficientes que possam ser usadas na prática.

Segundo Dubey, Schares e Ortega-Mora (2007), biossegurança compreende as ações que visam impedir a entrada de determinado patógeno ou agente em uma população animal. Para a neosporose bovina, segundo este mesmo autor, medidas de biosegurança devem ser tomadas para se evitar a entrada e disseminação do agente em um rebanho livre ou mesmo infectado, ou seja, com intuito de diminuir tanto a transmissão horizontal como a vertical. Dentre as medidas de prevenção as mais indicadas são fazer o uso somente de receptoras soronegativas na transferência de embrião; evitar o acesso de cães a tecidos infectados como fetos abortados, fluidos e restos de placentas, bem como o acesso aos comedouros e bebedouros, mantendo sempre os alimentos em lugares fechados; uso de maternidades individuais (REITEROVA et al., 2009) e controle de roedores (DUBEY, SCHARES E ORTEGA-MORA, 2007).

Dubey, Schares e Ortega-Mora (2007) citam que um controle correto da neosporose nos rebanhos inclui o abate dos animais soropositivos e a retirada da reprodução os animais nascidos de mães comprovadas para $N$. caninum, além do tratamento e vacinação de animais susceptíveis e infectados com o agente. Apesar disso, devido às altas taxas de prevalência observadas em algumas regiões do Brasil, o descarte dos animais soropositivos no controle em uma propriedade não é economicamente viável, apesar de matematicamente mais eficiente, principalmente no curto prazo (HASLER et al., 2006). A presença de um animal soropositivo em uma propriedade com histórico de abortos comprovados em resultado sorológico, não infere que o descarte deve ser realizado, uma vez que muitos animais soropositivos podem ter abortado 
BRUHN, F.R.P. et al. Neosporose em ruminantes. PUBVET, Londrina, V. 6, N. 2, Ed. 189, Art. 1276, 2012.

por outras causas. A melhor maneira de prevenção e controle da doença é realizar análise soroepidemiológica e conhecer o histórico reprodutivo. A compra de animais comprovadamente negativos para $N$. caninum é uma importante forma de prevenção (DUBEY, SCHARES E ORTEGA-MORA, 2007).

Assim, é importante no controle da neosporose atuar sobre as duas formas de transmissão do agente: a vertical, através da utilização da utilização de sêmen de raças de corte em vacas soropositivas para $N$. caninum (ALMERIA et al., 2009a), e a transmissão horizontal, por meio da redução do contato de cães com os animais de interesse reprodutivo (CORBELLINI et al., 2006). Estas medidas podem trazer bons resultados, principalmente no que tange a redução dos custos associados ao diagnóstico, prevenção e controle do agente.

É importante ressaltar que, de acordo com Dubey, Schares e OrtegaMora (2007), não é possível aplicar medidas gerais de controle efetivo, uma vez que cada região possui uma característica epidemiológica específica na neosporose. Assim, é prudente observar essas características antes de se realizar um programa de controle dessa doença.

\section{EPIDEMIOLOGIA}

Segundo Dubey, Schares e Ortega-Mora (2007) para se entender a epidemiologia do $N$. caninum é importante conhecer a abrangência do agente e a sua distribuição geográfica.

Segundo Bartels et al. (2006), a soroprevalência para $N$. caninum em bovinos pode variar entre 16 a $94 \%$ entre rebanhos e 0,5 a $30 \%$ entre animais, dependendo do país e da região, sendo que esta variação pode ocorrer em função da diferente exposição aos fatores de risco existentes em cada região.

Estudos soroepidemiológicos já foram realizados em diferentes regiões do Brasil. Em Minas Gerais, a soroprevalência ao N. caninum se apresenta bastante oscilante entre vacas leiteiras de diferentes rebanhos, podendo variar de 6,8\% (COSTA et al., 2001) a 91,2\% (SANTOS et al., 2009). Na Amazônia, 
BRUHN, F.R.P. et al. Neosporose em ruminantes. PUBVET, Londrina, V. 6, N. 2, Ed. 189, Art. 1276, 2012.

até então livre do agente, foi encontrada uma prevalência para $N$. caninum de $8,8 \%$ em vacas e $72 \%$ entre fazendas (AGUIAR et al., 2006). A ausência do $N$. caninum em algumas regiões, provavelmente, está mais relacionada à escassez de estudos soroepidemiológicos que possam demonstrar a realidade epidemiológica da doença no Brasil que a falta do agente. Em outro estudo realizado por Corbellini et al. (2006) na região Sul, foi verificada uma soroprevalência de $17,8 \%$ para animais, e $93,3 \%$ entre rebanhos. Santos et al. (2010) em gado de corte na Bahia verificaram soroprevalência de $20 \%$.

$\mathrm{Na}$ Europa, existe uma grande diferença na soroprevalência entre paises, como Espanha ( $63 \%$ em gado leiteiro e $46 \%$ em gado de corte), Alemanha ( $49 \%$ em gado leiteiro e $41 \%$ em gado de corte) e Holanda ( $76 \%$ em gado leiteiro e $61 \%$ em gado de corte) (BARTELS et al., 2006). Loobuyck et al. (2009) verificaram soroprevalência de $2,8 \%$ em vacas de leite na Suécia, valor bem abaixo que aqueles encontrados em algumas regiões brasileiras e européias.

Em avaliação soroepidemiologica na África, Kamga-Waladjo et al. (2010) demonstraram a alta difusão do agente neste continente, com uma prevalência de $17,9 \%$ entre animais e de $100 \%$ entre as fazendas produtoras de leite.

Existem evidências que sugerem que bovinos leiteiros são mais susceptíveis a infecção por $N$. caninum que bovinos de corte, talvez em função do sistema de criação mais intensivo que favorece a infecção pelo agente (ALMERIA et al., 2009a).

Há dois tipos de transmissão transplacentária para $N$. caninum, a endógena e a exógena (DUBEY, SCHARES E ORTEGA-MORA, 2007; BASSO et al., 2010). Esta classificação é epidemiologicamente importante, pois estão associados a dois tipos de abortos no rebanho bovino, o endêmico e o epidêmico (BASSO et al., 2010). No primeiro, a ocorrência do aborto se distribui ao longo do ano, em baixas quantidades, sendo que a sua ocorrência depende da ativação de uma infecção parasitária pré-existente. Em surtos de abortos epidêmicos, mais de $10 \%$ das vacas abortam em um período de quatro 
BRUHN, F.R.P. et al. Neosporose em ruminantes. PUBVET, Londrina, V. 6, N. 2, Ed. 189, Art. 1276, 2012.

a oito semanas. Este último depende da exposição das vacas a uma fonte contaminante comum (DUBEY, SCHARES E ORTEGA-MORA, 2007).

Pouco se sabe sobre os diferentes genótipos de $N$. caninum causadores de aborto, mas recentes estudos de biologia molecular podem ajudar a esclarecer esses pontos (Basso et al. 2010). Estudo realizado por Basso et al., (2010) demonstrou que: em situações de abortos epidêmicos existe só uma cepa do parasito relacionada ao surto, uma vez que a fonte infectante dos animais é a mesma. Apesar disso, acredita-se ser possível que cães eliminem diferentes cepas se estes se alimentarem de diferentes tecidos, o que poderia gerar uma infecção mista, mesmo em condições de abortos epidêmicos, após contaminação horizontal das vacas e transmissão vertical transplacentária exógena aos fetos (BASSO et al., 2010).

Alguns fatores de risco têm sido relacionados às infecções por $N$. caninum. Segundo Dubey, Schares e Ortega-Mora (2007) para aumentar a evidência se de fato um fator estudado é um verdadeiro fator de risco deve-se realizar a repetição dos estudos. Além disso, este tipo de estudo auxilia na minimização das perdas produtivas por meio do fornecimento de informações que possam auxiliar na prevenção e controle de doenças. O conhecimento dos fatores de risco associados à prevalência do $N$. caninum e à ocorrência de abortos relacionados a neosporose também auxiliam na implementação de métodos de controle da doença nos rebanhos. A maior parte do conhecimento sobre os fatores associados à ocorrência da neosporose é obtido a partir de estudos retrospectivos transversais ou de caso-controle (DUBEY, SCHARES e ORTEGA-MORA, 2007).

A susceptibilidade do hospedeiro favorece uma maior exposição, devido à existência de vários mecanismos que possibilitam a disseminação da doença. Por exemplo, a presença de fetos abortados ou restos placentários constituem fontes de infecção do agente principalmente aos hospedeiros definitivos (cães), que passam a contaminar o ambiente com oocistos nas fezes. Dessa forma ocorre a transmissão horizontal do agente aos hospedeiros intermediários, podendo causar o aborto. Neste sentido, segundo Williams et al. (2009), uma 
BRUHN, F.R.P. et al. Neosporose em ruminantes. PUBVET, Londrina, V. 6, N. 2, Ed. 189, Art. 1276, 2012.

vaca infectada com $N$. caninum tem de três a sete vezes mais probabilidade de abortar que uma não infectada.

O risco de infecção dos hospedeiros susceptíveis aumenta quando diferentes espécies que participam do mesmo ciclo de vida de um agente são criadas no mesmo ambiente em contato direto ou indireto. Estudo realizado por Vanleeuwen et al. (2010), em rebanhos bovinos, os fatores de risco estão associados à presença de cães, principalmente em propriedades rurais onde foi relatada ocorrência de sinais clínicos da neosporose. Neste mesmo estudo foi verificado que independente se cães se alimentam ou não de restos de placentas ou fetos abortados, sua presença constitui um fator de risco à ocorrência da neosporose. Isso corrobora com os resultados de Corbellini et al. (2006), que verificaram que vacas de fazendas menores em território apresentavam maiores chances de serem soropositivas para o agente em relação a vacas de fazendas maiores, pois, segundo estes mesmos autores, em fazendas menores os cães têm um maior contato com as vacas, e assim, maiores chances de se infectar $e$, consequentemente contaminar o ambiente com oocistos eliminados nas fezes, aumentando o risco de transmissão horizontal. Por outro lado, Aguiar et al. (2006) observaram ausência desta relação de risco entre a presença de cães nas propriedades e a taxa de soropositividade para $N$. caninum em rebanhos bovinos, na região amazônica.

More et al. (2009) verificou que vacas leiteiras com histórico de aborto têm mais chance de serem soropositivas para $N$. caninum em relação as que não abortaram e que femeas de corte. Isso confirma a existência da relação entre problemas reprodutivos em bovinos com a neosporose, assim como, a evidência desta relação com tipo de exploração (gado leiteiro ou de corte).

Outro fator de risco para a neosporose nas propriedades leiteiras é a utilização de pool de colostro, ou seja, colostro de várias vacas diferentes que é fornecido aos bezerros, o que pode propiciar uma possível transmissão do $N$. caninum pela via lactogênica (CORBELLINI et al., 2006).

Aguiar et al. (2006) verificaram que rebanhos leiteiros com mais de 25 vacas apresentam um risco quase dez vezes maior de apresentar o agente em 
BRUHN, F.R.P. et al. Neosporose em ruminantes. PUBVET, Londrina, V. 6, N. 2, Ed. 189, Art. 1276, 2012.

relação aos com de até 25 animais. Em estudo semelhante, Almeria et al. (2009a) demonstraram que o manejo intensivo dos rebanhos está associado a uma maior prevalência de $N$. caninum nos animais.

Existem evidências de que a soroprevalência para $N$. caninum possa variar de acordo com a raça dos animais (ALMERIA et al., 2009a). Segundo Bartels et al. (2006), algumas raças de corte nativas da Espanha, pastando em baixas densidades possuem maior resistência a neosporose que outras raças, enquanto algumas raças nativas da Suécia apresentam maior suceptibilidade a doença. Kamga-Waladjo et al. (2010) também verificaram diferenças na suceptibilidade de bovinos leiteiros ao parasito em função do tipo de raça (nativa, exótica ou cruzada). Porém, existem diferenças, principalmente em relação ao sistema de produção e não propriamente a susceptibilidade à infecção por determinada raça, o que faz necessário cautela na interpretação dos resultados (DUBEY, SCHARES E ORTEGA-MORA, 2007).

Almeria et al. (2009a), verificaram que vacas holandesas inseminadas com sêmen proveniente de touros de corte, especialmente da raça Limousin apresentam menores taxas de aborto em decorrência do $N$. caninum, quando comparados com aquelas inseminadas com sêmen de touro de mesma raça da vaca da fêmea. Nesse estudo foi observado que vacas soropositivas inseminadas com sêmen de touros da raça Limousin apresentavam uma taxa de aborto estatisticamente igual a taxas de aborto de vacas soronegativas. Isso ocorre, provavelmente, em função de uma menor passagem de parasitas pela placenta de vacas com feto mestiço, em comparação a placenta de gestação com fetos de raças não mestiças.

Maiores taxas de abortos em fetos apresentando lesões cerebrais foram relatadas em animais com níveis altos de anticorpos anti- $N$. caninum, uma vez que isso pode significar um aumento no número de parasitos, o que elevaria a ocorrência de lesões cerebrais e aborto fetal (ALMERIA et al., 2009a). Além disso, Kamga-Waladjo et al. (2010) observaram que vacas soropositivas para $N$. caninum apresentam piores índices reprodutivos relativos ao número de inseminação necessárias para a concepção e intervalo entre partos, em 
BRUHN, F.R.P. et al. Neosporose em ruminantes. PUBVET, Londrina, V. 6, N. 2, Ed. 189, Art. 1276, 2012.

comparação as soronegativas, em função da perda fetal logo no início da gestação.

Segundo Vanleeuwen et al. (2010), a utilização de transferência de embrião constitui um fator de proteção contra a neosporose, bem como, outras medidas relacionadas a um maior cuidado do produtor com a sanidade do seu rebanho, que segundo os autores, indiretamente se relacionam a menor soroprevalência do $N$. caninum nos animais.

Da mesma forma que em bovinos, existem potenciais fatores de risco associados a infecção por $N$. caninum em caprinos e ovinos, tais como: presença de cães, a idade dos animais, sexo, acesso de cães às fontes de água e comedouros. Soares et al. (2009) verificou na região nordeste, estado do Rio Grande do Norte, uma baixa soroprevalência entre ovelhas $(1,8 \%)$, o que está de acordo com outros trabalhos realizados em outras regiões do Brasil, com exceção do estado de Rondônia, que apresenta maior soroprevalência. Em estudo semelhante, (UENO et al., 2009) observou soroprevalência de 8,81\% em ovelhas no Distrito Federal.

De acordo com Faria et al. (2010) no estado de Alagoas, foi verificado uma prevalência de 9,6\% em ovelhas, e entre fazendas a ocorrência do agente foi de 53,8\%, o que demonstra a grande dispersão do agente na região estudada. Neste mesmo estudo foi verificado que em fazendas menores ou iguais a 30 hectares os animais apresentavam 7,23 mais chances de apresentar soropositividade para o agente, provavelmente em função da maior densidade de criação e maior contato de cães com as ovelhas.

Em ovelhas a transmissão horizontal também é importante, pois Faria et al. (2010) verificaram que animais que bebiam água tanto de fontes naturais, poços ou água tratada apresentavam 4,76 mais chance de apresentarem-se soropositivo para $N$. caninum, em relação aos animais que bebiam água somente de poços. Apesar disso, Soares et al. (2009) verificaram ausência de relação entre presença de cães nas propriedades em contato com ovelhas e uma maior chance de apresentar soropositividade para o N. caninum. 
BRUHN, F.R.P. et al. Neosporose em ruminantes. PUBVET, Londrina, V. 6, N. 2, Ed. 189, Art. 1276, 2012.

\section{REFERÊNCIAS}

AGUIAR, D. M. et al. Prevalence of anti-Neospora caninum antibodies in cattle and dogs from Western Amazon, Brazil, in association with some possible risk factors. Veterinary Parasitology, v. 142, n. 1-2, p. 71-77, 2006.

ALMERIA, S. et al. Fetal death in cows experimentally infected with Neospora caninum at 110 days of gestation. Veterinary Parasitology, v. 169, n. 3-4, p. 304-311, 2010.

ALMERIA, S. et al. Effects of crossbreed pregnancies on the abortion risk of Neospora caninum-infected dairy cows. Veterinary Parasitology, v. 163, n. 4, p. 323-329, 2009. a

ALMERIA, S. et al. Specific anti-Neospora caninum IgG1 and IgG2 antibody responses during gestation in naturally infected cattle and their relationship with gamma interferon production. Veterinary Immunology and Immunopathology [S.I.], v. 130, n. 1-2, p. 35-42, 2009. b

ANUALPEC - Anuário da Pecuária Brasileira. São Paulo: FNP, 2010.

BARTELS, C. J. M. et al. Supranationl comparison of Neospora caninum seroprevalences in cattle in Germany, the Netherlands. Spain and Sweden. Veterinary Parasitology [S.I], v. 137, p. 17-27, 2006.

BASSO, W. et al. Microsatellite typing and avidity analysis suggest a common source of infection in herds with epidemic Neospora caninum-associated bovine abortion. Veterinary Parasitology [S.I.], v. 173, n. 1-2, p. 24-31, 2010.

BJORKMAN, C. et al. Seroprevalence of Neospora caninum in gray wolves in Scandinavia. Veterinary Parasitology [S.I.], v. 173, n. 1-2, p. 139-142, 2010.

CORBELLINI, L. G. et al. Herd-level risk factors for Neospora caninum seroprevalence in dairy farms in southern Brazil. Preventive Veterinary Medicine [S.I.], v. 74, n. 2-3, p. 130-141, 2006.

COSTA, G. H. N. et al. Freqüência de anticorpos anti-Neospora caninum e anti-Toxoplasma gondii em soros de bovinos pertencentes aos estados de São Paulo e Minas Gerais. Semina, v. 22 , n. 1, p. 61-66, 2001.

DUBEY, J. P.; BARR, B. C.; BARTA, J. R. Redescription of Neospora caninum and its differentiation from related coccidian. Int. J. Parasitol [S.I]., v.32, p.929-946, 2002.

DUBEY, J. P. ; SCHARES, G. ; ORTEGA-MORA, L. M. Epidemiology and control of neosporosis and Neospora caninum. Clinical Microbiology Reviews [S.I.], v. 20, n. 2, p. 323, 2007.

DUBEY, J. P.; LINDSAY, D.S. A review of Neospora caninum and neosporosis. Veterinary Parasitology, v. 67, n. 1-2, p. 1-59, 1996.

FARIA, E. B. et al. Risk Factors Associated with Neospora caninum Seropositivity in Sheep From the State of Alagoas, in the Northeast Region of Brazil. Journal of Parasitology [S.I.], v. 96, n. 1, p. 197-199, 2010.

FUCHS, N., SONDA, S., GOTTSTEIN, B. Differential expression of cell surface-and dense granule-associeted Neospora caninum proteins in tachyzoites and bradyzoites. Journal of Parasitology [S.I], v.84, p.753-758, 1998. 
GONDIM, L. F. et al. Coyotes (Canis latrans) are definitive hosts of Neospora caninum. International Journal for Parasitology, v. 34, p. 159-161, 2004.

HASLER, B. et al. Neospora caninum: Serological follow-up in dairy cows during pregnancy. Veterinary Parasitology [S.I.], v. 137, n. 3-4, p. 222-230, 2006.

HEMPHILL, A., GAJENDRAN, N., SONDA, S., Identification and characterisation of a dense granule-associated protein in Neospora caninum tachyzoites. International Journal for Parasitology, v.28, p.429-438, 1998.

KAMGA-WALADJO, A. R. et al. Seroprevalence of Neospora caninum antibodies and its consequences for reproductive parameters in dairy cows from Dakar-Senegal, West Africa. Tropical Animal Health and Production [S.I.], v. 42, n. 5, p. 953-959, 2010.

LOOBUYCK, M. et al. Seroprevalence and spatial distribution of Neospora caninum in a population of beef cattle. Preventive Veterinary Medicine [S.I.], v. 92, n. 1-2, p. 116-122, 2009.

MCALLISTER, M. M. et al. Dogs are definitive hosts of Neospora caninum. International Journal for Parasitology [S.I], v. 28, n. 9, p. 1473-1478, 1998.

MOORE, D. P. et al. Risk factors associated with Neospora caninum infections in cattle in Argentina. Veterinary Parasitology [S.I.], v. 161, n. 1-2, p. 122-125, 2009.

MORE, G. et al. Frequency of horizontal and vertical transmission for Sarcocystis cruzi and Neospora caninum in dairy cattle. Veterinary Parasitology [S.I.], v. 160, n. 1-2, p. 51-54, 2009.

MORÉ, G. et al. Diagnosis of Sarcocystis cruzi, Neospora caninum, and Toxoplasma gondii infections in cattle. Parasitology Research [S.I.], v. 102, n. 4, p. 671-675, 2008.

PESCADOR, C. A. et al. Histopathological and immunohistochemical aspects of Neospora caninum diagnosis in bovine aborted fetuses. Veterinary Parasitology [S.I.], v. 150, n. 12, p. 159-163, 2007.

REICHEL, M. P.; ELLIS, J. T. Neospora caninum - How close are we to development of an efficacious vaccine that prevents abortion in cattle? International Journal for Parasitology [S.I.], v. 39, n. 11, p. 1173-1187, 2009.

REICHEL, M. P.; ROSS, G. P.; MCALLISTER, M. M. Evaluation of an enzyme-linked immunosorbent assay for the serological diagnosis of Neospora caninum infection in sheep and determination of the apparent prevalence of infection in New Zealand. Veterinary Parasitology [S.I.], v. 151, n. 2-4, p. 323-326, 2008.

REITEROVA, K. et al. Neospora caninum, potential cause of abortions in dairy cows: The current serological follow-up in Slovakia. Veterinary Parasitology [S.I.], v. 159, n. 1, p. 16, 2009.

ROITT, I.M.; BROSTOFF, J.; MALE, D.K. Imunologia. 5. ed., São Paulo: Ed. Helvética, 1999.

ROJO-MONTEJO, S. et al. Isolation and characterization of a bovine isolate of Neospora caninum with low virulence. Veterinary Parasitology [S.I.], v. 159, n. 1, p. 7-16, 2009. 
SANTOS, S. L. et al. Investigation of Neospora caninum, Hammondia sp., and Toxoplasma gondii in tissues from slaughtered beef cattle in Bahia, Brazil. Parasitology Research [S.I.], v. 106, n. 2, p. 457-461, 2010.

SOARES, H. S. et al. Prevalence of anti-Toxoplasma gondii and anti-Neospora caninum antibodies in sheep from Mossoro, Rio Grande do Norte, Brazil. Veterinary Parasitology [S.I.], v. 160, n. 3-4, p. 211-214, 2009.

SANTOS, R. R. D. et al. Frequência de anticorpos anti-Neospora caninum em bezerras e novilhas de rebanhos leiteiros na microrregião de Lavras, Minas Gerais. Ciência Animal Brasileira, v. 10, n. 1, p. 271-280, 2009.

STROHBUSCH, M. et al. Neospora caninum and bone marrow-derived dendritic cells: parasite survival, proliferation, and induction of cytokine expression. Parasite Immunology [S.I.], v. 31, n. 7, p. 366-372, 2009.

SUTEU, O. et al. First identification of Neospora caninum by PCR in aborted bovine foetuses in Romania. Parasitology Research [S.I.], v. 106, n. 3, p. 719-722, 2010.

TREES, A. J.; WILLIAMS D. J. L. Endogenous and exogenous transplacental infection in Neospora caninum and Toxoplasma gondii. Trends in Parasitology, v. 21, p. 558-561, 2005.

UENO, T. E. H. et al. Prevalence of Toxoplasma gondii and Neospora caninum infections in sheep from Federal District, central region of Brazil. Tropical Animal Health and Production [S.I.], v. 41, n. 4, p. 547-552, 2009.

VANLEEUWEN, J. A. et al. Risk factors associated with Neospora caninum seropositivity in randomly sampled Canadian dairy cows and herds. Preventive Veterinary Medicine [S.I.], v. 93, n. 2-3, p. 129-138, 2010.

WAPENAAR, W. et al. Comparison of serological methods for the diagnosis of Neospora caninum infection in cattle. Veterinary Parasitology [S.I.], v. 143, n. 2, p. 166-173, 2007.

WILLIAMS, D. J. L. et al. Endogenous and exogenous transplacental transmission of Neospora caninum - how the route of transmission impacts on epidemiology and control of disease. Parasitology [S.I.], v. 136, n. 14, p. 1895-1900, 2009.

YAO, L. et al. Detection of Neospora caninum in aborted bovine fetuses and dam blood samples by nested PCR and ELISA and seroprevalence in Beijing and Tianjin, China. Parasitology [S.I.], v. 136, n. 11, p. 1251-1256, 2009.

YILDIZ, K. et al. Seroprevalence of Neospora caninum in dairy cattle ranches with high abortion rate: Special emphasis to serologic co-existence with Toxoplasma gondii, Brucella abortus and Listeria monocytogenes. Veterinary Parasitology [S.I.], v. 164, n. 2-4, p. 306310, 2009. 